\title{
The Evolution of Device-Assisted Enteroscopy: From Sonde Enteroscopy to Motorized Spiral Enteroscopy
}

\author{
Fredy Nehme ${ }^{1}$, Hemant Goyal ${ }^{2 *}$, Abhilash Perisetti ${ }^{3}$, Benjamin Tharian ${ }^{4}$, Neil Sharma ${ }^{5,6}$, \\ Tony C. Tham ${ }^{7}$ and Rajiv Chhabra ${ }^{1}$
}

${ }^{1}$ Department of Gastroenterology and Hepatology, School of Medicine, Saint Luke's Hospital, University of Missouri Kansas City (UMKC), Kansas City, MO, United States, ${ }^{2}$ Department of Medicine, The Wright Center for Graduate Medical Education, Scranton, PA, United States, ${ }^{3}$ Division of Interventional Oncology and Surgical Endoscopy (IOSE), Parkview Cancer Institute, Fort Wayne, IN, United States, ${ }^{4}$ Department of Gastroenterology and Hepatology, University of Arkansas for Medical Sciences, Little Rock, AR, United States, ${ }^{5}$ Division of Interventional Oncology and Surgical Endoscopy (IOSE), Parkview Cancer Institute, Fort Wayne, IN, United States, ${ }^{6}$ Department of Endoscopy, Indiana University School of Medicine, Fort Wayne, IN, United States, ${ }^{7}$ Division of Gastroenterology, Ulster Hospital, Belfast, United Kingdom

OPEN ACCESS

Edited by:

Cristiano Spada

Fondazione Poliambulanza Istituto

Ospedaliero, Italy

Reviewed by:

Ervin Toth,

Skåne University Hospital, Sweden

Rami Eliakim,

Sheba Medical Center, Israel

Marianna Arvanitakis,

Free University of Brussels, Belgium

*Correspondence: Hemant Goyal doc.hemant@yahoo.com

Specialty section:

This article was submitted to Gastroenterology,

a section of the journal

Frontiers in Medicine

Received: 11 October 2021 Accepted: 22 November 2021 Published: 23 December 2021

Citation:

Nehme F, Goyal H, Perisetti A Tharian B, Sharma N, Tham TC and Chhabra R (2021) The Evolution of Device-Assisted Enteroscopy: From Sonde Enteroscopy to Motorized Spiral Enteroscopy.

Front. Med. 8:792668.

doi: 10.3389/fmed.2021.792668
The introduction of capsule endoscopy in 2001 opened the last "black box" of the gastrointestinal tract enabling complete visualization of the small bowel. Since then, numerous new developments in the field of deep enteroscopy have emerged expanding the diagnostic and therapeutic armamentarium against small bowel diseases. The ability to achieve total enteroscopy and visualize the entire small bowel remains the holy grail in enteroscopy. Our journey in the small bowel started historically with sonde type enteroscopy and ropeway enteroscopy. Currently, double-balloon enteroscopy, singleballoon enteroscopy, and spiral enteroscopy are available in clinical practice. Recently, a novel motorized enteroscope has been described with the potential to shorten procedure time and allow for total enteroscopy in one session. In this review, we will present an overview of the currently available techniques, indications, diagnostic yield, and complications of device-assisted enteroscopy.

Keywords: double-balloon enteroscopy (DBE), deep enteroscopy, spiral enteroscopy, device-assisted enteroscopy, motorized enteroscopy, small bowel

\section{INTRODUCTION}

Up until the end of the $20^{\text {th }}$ century, the available options for small bowel evaluation were limited owing to the length of the small intestine and its anatomy. Push enteroscopy, the main technique, had a limited insertion depth and diagnostic yield (1). Intraoperative enteroscopy allowed complete small bowel evaluation but was associated with a high morbidity and mortality approaching 17 and $5 \%$ respectively (2). Capsule endoscopy was first reported in 2001 opening up the small bowel for diagnostic approaches, but was not able to close the gap in therapeutic interventions (3) (Table 1). The introduction of double-balloon enteroscopy (DBE) in 2001 enabled endoscopic scrutiny of the entire small bowel with intervention capabilities such as tissue sampling with biopsies, mucosal injection, polypectomy, hemostatic techniques, stricture dilation, and retrieval of foreign bodies (4). DBE remains the most studied and established deep enteroscopy (DE) technique to date. Additional methods were later introduced such as single-balloon enteroscopy (SBE) in 2007 (5) and spiral enteroscopy (SE) in 2008 (6). A novel motorized spiral enteroscope was described in 2015 allowing 
TABLE 1 | Diagnostic yield of video capsule endoscopy for various indications.

\begin{tabular}{lc}
\hline Indication & Diagnostic yield (\%) \\
\hline Obscure gastrointestinal bleeding & 44 \\
Acute gastrointestinal bleeding & $64-87$ \\
Abdominal pain & $3-21$ \\
NSAID enteropathy & $5-60$ \\
Crohn's disease & $39-50$ \\
Celiac disease & 54 \\
Familial adenomatous polyps & 29 \\
Peutz-Jeghers Syndrome & $22-59$
\end{tabular}

faster and easier progression into the small bowel (7). These techniques are known as "device-assisted enteroscopy" (DAE). $\mathrm{DAE}$ is a generic term for assisted progression of the enteroscope into the small bowel. Assistance is provided by overtubes, balloon catheters, or other stiffening devices (8-10).

The field of DAE continues to evolve with the development of new enteroscopes taking therapeutic endoscopy in the small bowel to another level. Endoscopic retrograde cholangiopancreatography (ERCP) and even cholangioscopy are nowadays feasible with the help of DAE in patients with altered anatomy (11). In this review, we will highlight the latest DAE developments, the emerging clinical results, and future directions.

\section{HISTORICAL DEVICE-ASSISTED ENTEROSCOPY TECHNIQUES}

\section{Sonde Type Enteroscopy}

The first successful total enteroscopy was reported in 1971 using a ropeway and a sonde method. The sonde type consisted of a 5$\mathrm{mm}$ forward-viewing fibroscope that can be passed transnasally and migrates distally to the stomach. It is then pushed through the pylorus with a gastroscope passed through the mouth and carried by peristalsis of a balloon inflated at the tip (12). The procedure was uncomfortable, painful, and lasted 6-8 h. It also did not allow tissue sampling, tip deflection, or therapeutic interventions. Only $50-80 \%$ of the mucosa could be visualized and up to $75 \%$ of the time, the terminal ileum could not be visualized (13).

\section{Ropeway Type Enteroscopy}

The ropeway enteroscope consists of insertion of a long intestinal Teflon string that is advanced orally and discharged from the anus. Once this step is finished, typically requiring $24 \mathrm{~h}$, the ropeway enteroscope can be pulled through the gastrointestinal tract with the aid of the string. Visualization and biopsy of the small bowel are possible, however traction on the string increases the risk of perforation and stenotic lesions disallowed the passage of the string and limited the effectiveness of this device $(14,15)$. The sonde and ropeway methods were cumbersome, technically challenging, time-consuming, and did not achieve wide acceptance in clinical practice. They have since been replaced by more effective deep enteroscopy techniques.

\section{CURRENT DEVICE-ASSISTED ENTEROSCOPY TECHNIQUES}

\section{Push Enteroscopy}

For nearly 30 years, push enteroscopy (PE) was the preferred method and consisted of using a long endoscope with a standard diameter allowing visualization of the esophagus, stomach, duodenum, and proximal jejunum. Bleeding sources in the proximal small bowel up to $50-70 \mathrm{~cm}$ from the pylorus can be rapidly excluded with this method, however visualization of the entire small bowel is not possible. Compared to other DAE, $\mathrm{PE}$ has shorter sedation and procedure time while antegrade balloon-enteroscopy has significantly greater depth of insertion (230 vs $80 \mathrm{~cm}, p<0.001$ ) and diagnostic yield (63 vs $44 \%$, $p<0.001)$. In addition, deep enteroscopy identifies additional lesions in deeper parts of the small bowel in most PE-positive patients (16).

\section{Double-Balloon Enteroscopy}

The advent of video capsule endoscopy (VCE) in 2001 led to an increasing need for a reliable endoscopic method for direct access to the small bowel for histopathological confirmation or performance of endoscopic therapies. The development of DBE in 2001 resulted in a paradigm shift in diagnostic and therapeutic approaches in the small bowel. The DBE system (DBE, Fujifilm, Tokyo, Japan) comprises an enteroscope, an overtube, and a balloon-pump system with an inflatable balloon at the distal end of the enteroscope and a second balloon attached to the overtube. $\mathrm{DBE}$ may be performed in antegrade or retrograde manner and standard length endoscopic accessories can be used (17). After passing the duodenum or the ileo-cecal valve, the small bowel can be pleated by inflating and deflating the two balloons in tandem order leading to a much greater depth of insertion compared to push enteroscopy. This is known as a pull-and-push technique (18). There are three types of DBE available including a diagnostic, therapeutic, and a short model. The short DBE is engineered to overcome technically-challenging therapeutic ERCP procedures in patients with surgically altered anatomy.

The depth of intubation is estimated between $240 \mathrm{~cm}$ and $360 \mathrm{~cm}$ during the anterograde approach and $100-140 \mathrm{~cm}$ for the retrograde approach (19-21). Tee et al. found no distinct learning curve with antegrade DBE while technical success rates for retrograde DBE defined as achieving stable overtube placement in the ileum or finding the target lesion continued to increase over time during the study. The authors estimated at least 30-35 cases of retrograde DBE under supervision were needed to achieve a good technical success rate of more than $75 \%$ (22).

DBE is the most prospectively studied technique in terms of safety, diagnostic, and therapeutic yield. Total enteroscopy defined as the intubation of the entire small bowel was reported at $44 \%$ in a systematic review including $12,823 \mathrm{DBE}$ procedures with an overall diagnostic yield of $68.1 \%$ (23).

Complications associated with DAE became increasingly recognized following the introduction of these new techniques. In addition to the known endoscopic complications of bleeding, perforation, and sedated associated complications, DBE has been associated with pancreatitis. Pooled minor and major 
adverse events in a large systematic review were $9.1 \%$ and $0.72 \%$ respectively (23).

The first reports of pancreatitis post DBE were published in 2006 (24). Several studies then reported up to 50\% of patients had high levels of amylase and lipase following DBE and a few developed clinical signs of acute pancreatitis $(25,26)$. In large cohorts, the frequency of pancreatitis was estimated at $0.2-$ $0.34 \%$ and the majority of the cases were reported with the antegrade route $(23,24)$. The pathogenesis of pancreatitis is thought to be secondary to mechanical stress on the pancreas or the papilla during the push-and-pull maneuver. One study noted a correlation between hyperamylasemia and the insertion depth and the number of pull maneuvers during DBE (27). Therefore, avoiding mechanical stress to the pancreas through slow retraction of the endoscope and the papilla by only using the balloon in deeper parts of the duodenum is recommended to reduce the risk of pancreatitis after DBE.

Bleeding after DBE has been reported particularly after interventional procedures. In a cohort of 2,362 DBE procedures, bleeding rate was $0.8 \%$ and only $0.1 \%$ after diagnostic procedures. The risk of perforation increases in those with prior abdominal surgeries. It is estimated at $0.1-0.3 \%$ in diagnostic procedures and $0.8-2.9 \%$ after small bowel polypectomy (28-30).

DAE are typically more time consuming than upper and lower gastrointestinal endoscopies and the risk of sedation-related complications should be taken into account. These complications were reported in $0.5 \%$ of cases in one database (28). Several studies have reported on the safety of DAE in the elderly $(31,32)$.

\section{Single-Balloon Enteroscopy}

The single-balloon enteroscope (SBE, Olympus Medical Systems Corporation, Tokyo, Japan) consists of one balloon attached to the tip of an overtube without the balloon attached to the tip of the endoscope. This was designed to streamline the pushand-pull technique leading to shorter set-up time, and less burdensome balloon control panel (33). The main technical difference between SBE and DBE is the need to angulate the tip of the SBE before the pulling maneuver to compensate for reduced stability (34). One diagnostic and one therapeutic SBE models are available.

The depth of intubation during antegrade SBE is between 133 to $256 \mathrm{~cm}$ past the ligament of Treitz and $73-163 \mathrm{~cm}$ for retrograde $\mathrm{SBE}$ past the ileocecal valve. The rate of complete enteroscopy is lower than DBE between 15 to $25 \%$ while the diagnostic yield is comparable at 47 to $60 \%$ (35-38). The range of therapeutic procedures offered is similar to DBE. Overall adverse event rate is also comparable to $\mathrm{DBE}$ at $1 \%$ with potentially higher risk of deep submucosal tears if the endoscope tip is flexed particularly in the setting of adhesions or strictures (39). The power suction maneuver consisting of maximum suction power to hold the small intestine during the insertion of the overtube may result in less damage to the mucosa than does the hook shape (40).

\section{Conventional Spiral Enteroscopy}

Spiral enteroscopy (Spirus Medical Inc., Stoughton, Massachusetts) was initially introduced in 2007 and consists of a manually rotatable overtube with a helical design called the Discovery Small Bowel that is positioned on a thin flexible enteroscope. The intestine is evaluated using a rotate-toadvance technology where the small bowel is retraced on the overtube with slight rotation allowing rapid advancement of the endoscope with a stable positioning. This allows meticulous examination of the small bowel on both insertion and withdrawal of the enteroscope (41). Most studies have described using spiral enteroscopy with the antegrade approach. The average depth of intubation ranges between $200 \mathrm{~cm}$ and $346 \mathrm{~cm}$ (42). Spiral enteroscopy allows reduction of total procedure time, with a similar diagnostic and therapeutic yields to DBE and a comparable depth of maximal insertion (DMI) $(42,43)$. The rate of total enteroscopy remains low barely approaching the $10 \%$ benchmark mainly due to difficult retrograde passage (43).

Akerman et al. reported major complication rates of $0.3 \%$. In 2,950 patients, 8 perforations were reported with no incidence of acute pancreatitis, suggesting that SE has a lower risk of acute pancreatitis than DBE and SBE (44). Studies suggest that only about 5 procedures are required for competency in SE by an otherwise trained endoscopist (45). Conventional spiral enteroscopy is no longer available in the market since the introduction of motorized spiral enteroscopy discussed below in detail.

\section{Balloon-Guided Endoscopy}

Balloon-guided endoscopy (NaviAid, Smart Medical Systems, Ra'anana, Israel) consists of a permanently integrated inflatable balloon at the tip of the endoscope (single-balloon) which can be used with an additional through-the-scope NaviAid AB balloon catheter through the working channel (double-balloon). The NaviAid AB balloon can also be used with a standard adult colonoscope with a $3.7 \mathrm{~mm}$ working channel, a principle called on-demand enteroscopy. The through-the-scope balloon catheter is advanced into the lumen and used as an anchoring device inside the small bowel to enable deep enteroscopy. Limited data reported a mean DMI of $120 \mathrm{~cm}$ for antegrade enteroscopy and $110 \mathrm{~cm}$ for retrograde enteroscopy with rapid procedure times $(46,47)$.

\section{Motorized Enteroscopy}

In 2015, clinical evaluation of the first motorized version of the SE system started with the first human case of PowerSpiral Enteroscopy (PSE, Olympus Medical Systems Corporation, Tokyo, Japan) (7). PSE consists of a $168 \mathrm{~cm}$ long flexible endoscope that is compatible with the latest EXERA III endoscopy system. It includes a large 3.2-mm accessory channel and a separate dedicated irrigation channel. These additions reduce challenges in small bowel therapeutics and potential wear and tear on the endoscopist with less instrument exchanges. The system incorporates a user-controlled electric motor embedded in the endoscope's handle to rotate the spiral tube attached on the endoscope's insertion tube. Rotation is activated by a foot pedal switch. While the overtube pleats the bowel on the insertion tube, the resistance applied to the tissue is measured via a LED display to prevent bowel damage (48). This reduces the resources needed for training and personnel. With PSE withdrawal, the endoscopist 


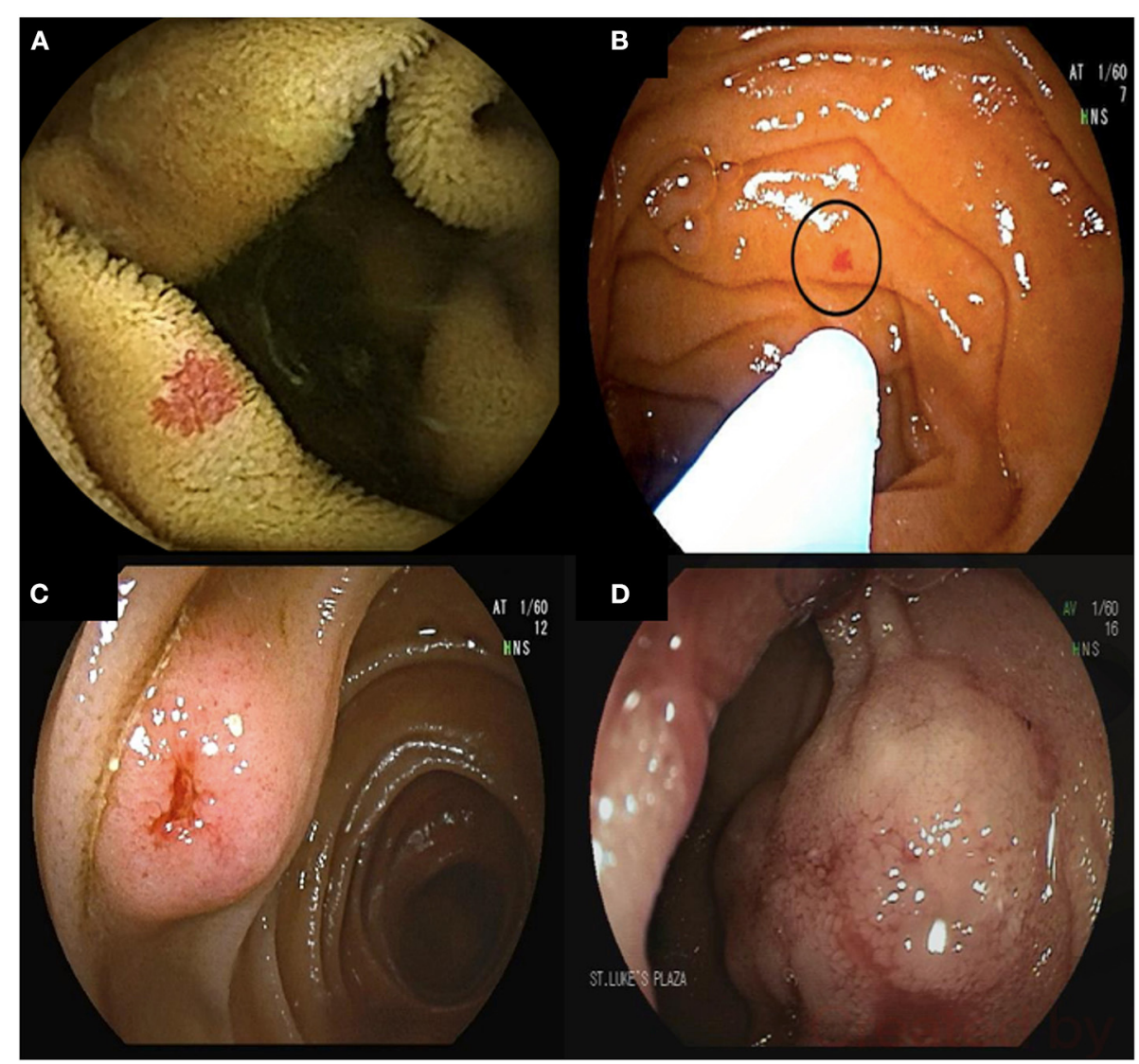

FIGURE 1 | 68-year-old male presented with melenic stools and a hemoglobin of $5.5 \mathrm{~g} / \mathrm{dL}$. Upper endoscopy and colonoscopy did not reveal the source of bleeding. Video capsule endoscopy revealed multiple proximal small bowel angioectasia (A). Antegrade double balloon enteroscopy was performed with successful ablation of angioectasia using argon plasma coagulation (B). Bleeding submucosal arteriovenous malformations (AVMs) found on deep enteroscopy requiring surgical resection (C,D).

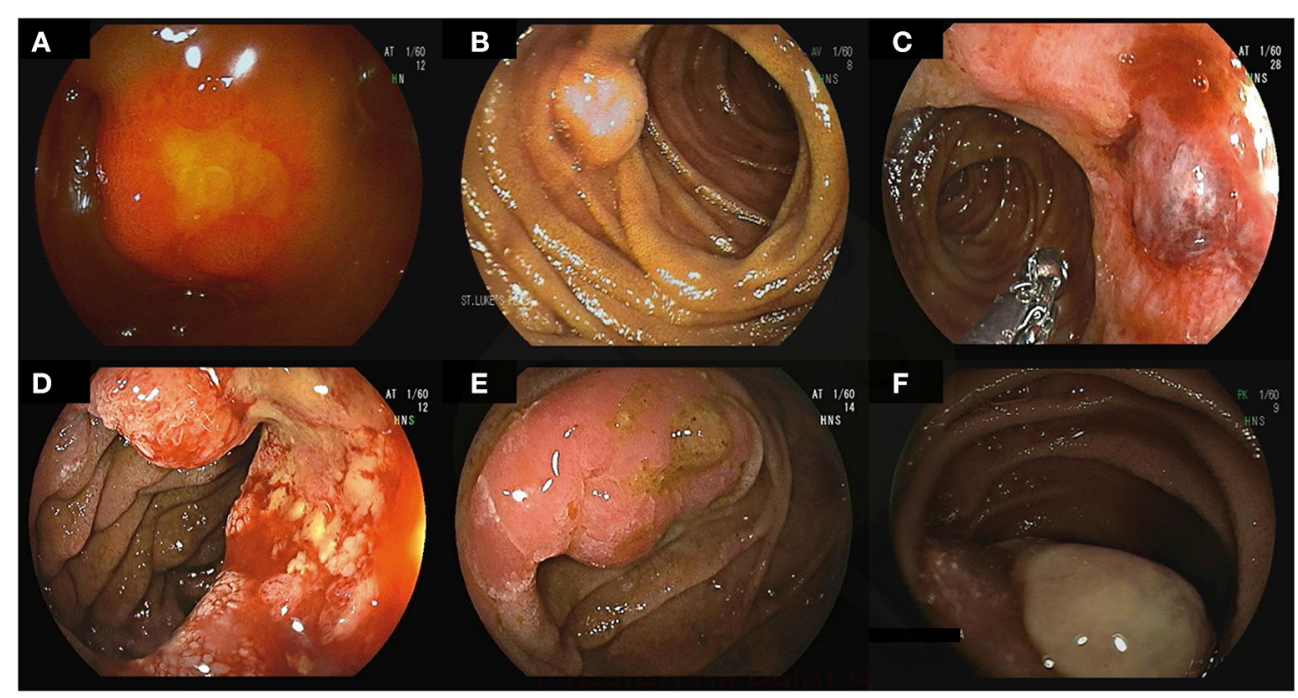

FIGURE 2 | Small bowel tumors and polyps found on deep enteroscopy: well differentiated neuroendocrine tumors in the ileum (A-C), moderately differentiated invasive adenocarcinoma in the jejunum (D), tubulovillous adenoma with low-grade dysplasia (E), small bowel metastasis secondary to renal cell carcinoma (F). 
should provide counterclockwise rotation to prevent the creation of shear forces and allow the small bowel to unscrew off the spiral.

In a prospective feasibility study of 140 peroral PSE procedures performed under general anesthesia, the technical success was $97 \%$ with diagnostic and therapeutic yields of $74.2 \%$ and $68.2 \%$ consecutively. The median DMI was $450 \mathrm{~cm}$ with a median insertion time of $25 \mathrm{~min}$. Panenteroscopy to the cecum was achieved in $10.6 \%$ of the cases. The adverse event rate was $14.4 \%$ including one delayed perforation and one bleeding Malory-Weiss lesion. The risk of pancreatitis appears significantly low $(49,50)$.

In a study including 30 patients with indications for total enteroscopy, the total enteroscopy rate was $70.6,16.6 \%$ with the antegrade approach alone and $53.4 \%$ with bidirectional approach (51). This rate seems to be comparable or even better than the rate of total enteroscopy in DBE of 40$60 \%$, and much better than SBE and SE given substantial improvement in retrograde enteroscopy success rate. DMI by the retrograde approach was reported at $140 \mathrm{~cm}$ during a median of $35 \mathrm{~min}$ (52). Shortened PSE procedure time is likely due to the elimination of the push and pull reduction with balloon enteroscopy. To note, prophylactic esophageal bougie dilation has been performed in clinical studies to aid passage of the PSE through the upper esophageal sphincter but the real-world necessity of this step remains unknown.

\section{CONVENTIONAL INDICATIONS FOR DEVICE-ASSISTED ENTEROSCOPY}

\section{Bleeding}

Small bowel bleeding remains the main indication for DAE and occurs in approximately $5 \%$ of patients presenting with GI hemorrhage $(53,54)$ (Figure 1).

The diagnostic yields of SBE and DBE in patients with small bowel bleed are similar ranging between $40-80 \%(21,55,56)$.

In a cost-effective study of patients with obscure GI bleeding, deep enteroscopy was the most cost-effective test after standard endoscopy for an endpoint of treatment or definitive diagnosis (57). Similarly, initial DE is a cost-effective approach for patients who likely have small bowel angiectasias (58). Initial VCE remains a common preferred strategy owing to its noninvasive nature.

Rebleeding rates for small bowel bleed after treatment during $\mathrm{DBE}$ were reported at $46 \%$ at 36 months in a large cohort of 261 patients. Risk factors for rebleeding include the total number of observed lesions and the presence of valvular or arrhythmic cardiac disease (59). May et al. showed a significant increase in hemoglobin levels and a decrease in blood transfusion requirements after therapy with argon plasma coagulation (APC) during DBE during a mean follow-up of 55 months (60). Other studies noted comparable rebleeding rates between patients with and without treatment of angiodysplasia (61).

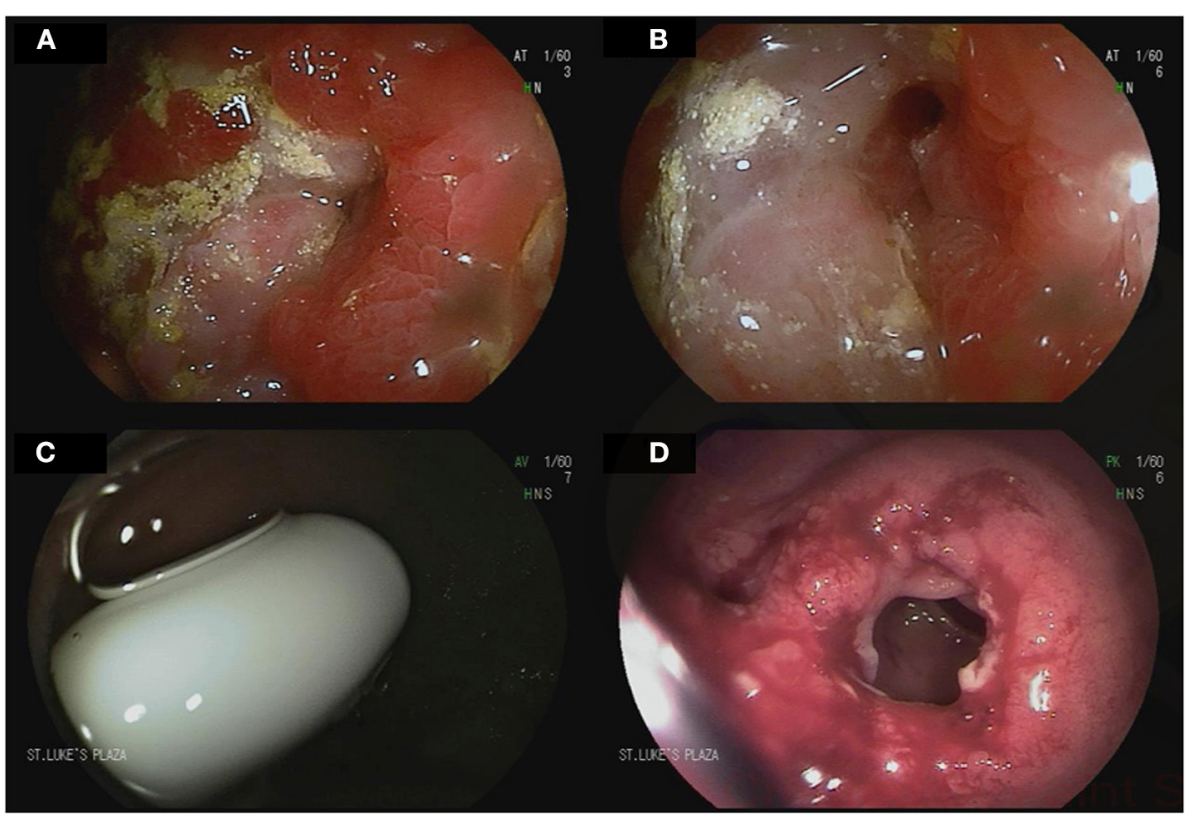

FIGURE 3 | Device-assisted enteroscopy in the setting of stricturing small bowel Crohn's disease. A 70-year-old male with history of small bowel Crohn's disease on Infliximab was referred for deep enteroscopy after a small bowel follow through showed a stricture in the distal jejunum. Antegrade double balloon enteroscopy showed severe stenosis with friability and ulcerations (A,B). Biopsies showed chronic enteritis with moderate activity. Biologic therapy for his Crohn's disease was adjusted accordingly. A 24-year-old male with small bowel Crohn's disease was referred for deep enteroscopy after retention of video capsule endoscopy in the small bowel. Retrograde double-balloon enteroscopy showed the capsule at the level of an ileal stricture (C). The stricture was dilated using through-the-scope balloon dilation (D). 


\section{Small Bowel Tumors and Polyps}

Small bowel tumors account for 3-6\% of all GI neoplasms (62). DAE techniques are effective in detecting and often treating small bowel tumors and polyps (Figure 2). The diagnostic yield for DBE in those with suspected small bowel pathology is between $9 \%$ to $14 \%(63-65)$. VCE was comparable to DBE in detection of small bowel tumors in a meta-analysis including 756 procedures (66). DE is also useful for patients in whom a suspicion for a small bowel tumor remains after a negative VCE. The reported miss-rate for small bowel tumors on VCE is $18.9 \%$ (67).

DE permits biopsy and tattoo placement to guide surgical resection in small bowel tumors. Endoscopic polypectomy has been reported in several studies without major complications. No differences were noted in the rates of therapeutic success between DBE and intraoperative enteroscopy, although the latter is much more invasive (68). Patients with polyposis syndromes can be managed endoscopically with DE decreasing the need for small bowel resections and short bowel syndrome (69).

\section{Crohn's Disease}

DAE is less commonly used in Crohn's disease owing to its invasive nature, although Crohn's disease lesions are commonly found when DBE is performed (Figure 3) (70-72). It is mainly used for therapeutic interventions including balloon dilation of small bowel strictures and to obtain histological diagnosis in those with small bowel disease. In Crohn's disease patients with clinically suspected small bowel disease, $60 \%$ had active small bowel lesions on DBE leading in change in therapy in $75 \%$ of the cases (73). DBE-assisted small bowel stricture dilation can delay or prevent surgery with an acceptable complication rate (74).

\section{INDICATIONS FOR DEVICE-ASSISTED ENTEROSCOPY OUTSIDE OF THE SMALL BOWEL}

With improvements in deep enteroscopy, additional indications have emerged including DAE-assisted colonoscopy, endoscopic access to GI segments out of reach to conventional endoscopes, and ERCP in patients with altered anatomy.

\section{DAE-Assisted Colonoscopy}

Overtube-assisted colonoscopy was shown to be useful in performing colonoscopy by increasing the cecal intubation rate and patient tolerance while decreasing the need for sedation (75). Cecal intubation rates were reported to exceed $90 \%$ in previous incomplete conventional colonoscopy (76). Singleballoon, double-balloon, and spiral enteroscopy were all reported to be effective and safe for this indication $(77,78)$. In addition, balloon overtube facilitates endoscopic submucosal dissection (ESD) by stabilizing the endoscope's position and improving maneuverability (79).

\section{DAE in Patients With Altered Anatomy}

DAE allows access to the excluded stomach in patients after Roux-en-Y gastric bypass allowing evaluation for bleeding and malignancy (Figure 4) $(80,81)$. Percutaneous endoscopic gastrostomy tube placement has also been described using DAE allowing permanent access to the upper gastrointestinal tract (82). Patients with intestinal surgical reconstruction can now benefit from DAE to evaluate or treat lesions out of reach to conventional endoscopes $(83,84)$. In particular, enteral

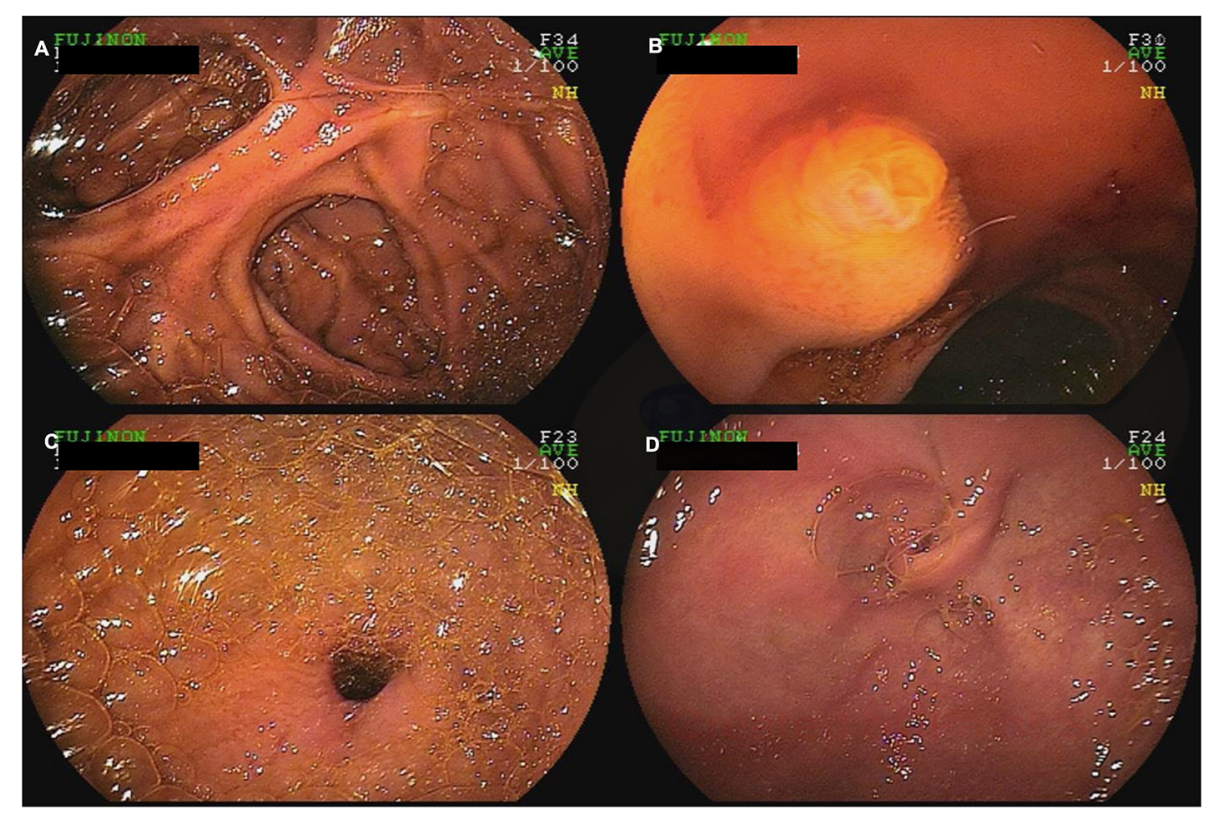

FIGURE 4 | A 60-year-old female with a history of Roux-en-Y gastric bypass and persistent abdominal pain despite extensive work-up was referred for deep enteroscopy for evaluation of the gastric remnant. Antegrade double-balloon enteroscopy was performed showing the jejuno-jejunal anastomosis (A), the major papilla (B), the pylorus (C), and the excluded stomach (D). 
TABLE 2 | Characteristics of currently available enteroscopy techniques.

\begin{tabular}{|c|c|c|c|c|c|c|c|c|}
\hline & Company & $\begin{array}{l}\text { Depth of maximal } \\
\text { insertion, antergrade }\end{array}$ & Diagnostic yield & $\begin{array}{c}\text { Total } \\
\text { enteroscopy rate }\end{array}$ & $\begin{array}{l}\text { Average procedure } \\
\text { time, antegrade } \\
\text { (minutes) }\end{array}$ & $\begin{array}{c}\text { Major complication rate } \\
\text { (\%) (includes perforation, } \\
\text { pancreatitis, bleeding) }\end{array}$ & Advantages & Disadvantages \\
\hline $\begin{array}{l}\text { Push } \\
\text { Enteroscopy }\end{array}$ & & $60-80 \mathrm{~cm}$ & $15-40 \%$ & $0 \%$ & 30 & $0.1-0.3$ & $\begin{array}{l}\text { - Shortest sedation and } \\
\text { procedure time } \\
\text { - Wide availability and ease } \\
\text { of use }\end{array}$ & $\begin{array}{l}\text { - Evaluation limited to proximal } \\
\text { jejunum }\end{array}$ \\
\hline $\begin{array}{l}\text { Double Balloon } \\
\text { Enteroscopy }\end{array}$ & $\begin{array}{l}\text { Fujifilm, } \\
\text { Tokyo, Japan }\end{array}$ & $220-360 \mathrm{~cm}$ & $40-80 \%$ & $40-60 \%$ & $60-123$ & $0.72-1.2$ & $\begin{array}{l}\text { - Higher depth of insertion and } \\
\text { total enteroscopy rate } \\
\text { compared to SBE } \\
\text { - Most studied technique in } \\
\text { safety and efficacy }\end{array}$ & $\begin{array}{l}\text { - Lengthy procedure time } \\
\text { - Longer time to achieve } \\
\text { competency } \\
\text { - Two operators required }\end{array}$ \\
\hline $\begin{array}{l}\text { Single Balloon } \\
\text { Enteroscopy }\end{array}$ & $\begin{array}{l}\text { Olympus, } \\
\text { Tokyo, Japan }\end{array}$ & $133-270 \mathrm{~cm}$ & $41-65 \%$ & $15-25 \%$ & $57-72$ & 0.02 & $\begin{array}{l}\text { - Shorter procedure time and } \\
\text { easier use compared to DBE }\end{array}$ & $\begin{array}{l}\text { - Lower depth of insertion and } \\
\text { total enteroscopy rate } \\
\text { compared to DBE }\end{array}$ \\
\hline $\begin{array}{l}\text { Balloon Guided } \\
\text { Endoscopy }\end{array}$ & $\begin{array}{l}\text { NaviAid, } \\
\text { Smart } \\
\text { Medical } \\
\text { Systems, } \\
\text { Israel }\end{array}$ & $120-190 \mathrm{~cm}$ & $45-59 \%$ & N/A & $15-52$ & Limited data & $\begin{array}{l}\text { - No special preloading and } \\
\text { preparation needed } \\
\text { - Device inserted via instrument } \\
\text { channel as needed }\end{array}$ & $\begin{array}{l}\text { - Very limited data on efficacy } \\
\text { and safety }\end{array}$ \\
\hline $\begin{array}{l}\text { Manual Spiral } \\
\text { Enteroscopy }\end{array}$ & $\begin{array}{l}\text { Spirus } \\
\text { Medical, } \\
\text { Stoughton, } \\
\text { Massachusetts }\end{array}$ & $175-262 \mathrm{~cm}$ & $30-65 \%$ & $10 \%$ & $35-52$ & 0.08 & $\begin{array}{l}\text { - Shorter procedure time } \\
\text { compared to balloon assisted } \\
\text { enteroscopy }\end{array}$ & $\begin{array}{l}\text { - Difficult retrograde passage } \\
\text { - Low total enteroscopy rate } \\
\text { - Two operators required }\end{array}$ \\
\hline $\begin{array}{l}\text { Motorized Spiral } \\
\text { enteroscopy }\end{array}$ & $\begin{array}{l}\text { Olympus, } \\
\text { Tokyo, Japan }\end{array}$ & $450-490 \mathrm{~cm}$ & $65-80 \%$ & $60-70 \%$ & 40 & 1.5 & $\begin{array}{l}\text { - Includes large } 3.2 \mathrm{~mm} \\
\text { accessory channel and a } \\
\text { separate irrigation channel } \\
\text { - Short procedure time and } \\
\text { easy to use } \\
\text { - Highest total enteroscopy rate }\end{array}$ & $\begin{array}{l}\text { Limited data on safety } \\
\text { - Prophylactic esophageal } \\
\text { dilation may be required } \\
\text { - Limited availability }\end{array}$ \\
\hline
\end{tabular}

SBE, single balloon enteroscopy, DBE, double balloon enteroscopy. 
insertion of self-expandable metal stents in intestinal segments previously excluded from endoscopic access has been described to treat malignant intestinal obstruction or strictures $(85,86)$. In addition, the newly developed shorter enteroscopes and the G-EYE enteroscopes allow through-the-scope deployment of enteral metal stents (83). However, DAE assisted enteroscopy in surgically altered anatomy is associated with an increased risk of small bowel perforation owing to adhesions (23).

\section{DAE-Assisted ERCP}

Billroth II partial gastrectomy, Whipple's procedure, and Rouxen-Y anatomy are prone to an increased risk of biliopancreatic complications while rendering ERCP with a conventional sideviewing duodenoscope difficult (87). In a systematic review including 945 DAE-assisted ERCP in surgically altered anatomy, ERCP success was $74 \%$, highest in patients with Billroth II and lowest in Roux-en-Y gastric bypass. The overall major adverse events was 3.4\% (88). Given reported technical challenges with DAE-assisted ERCP using conventional double or singleballoon enteroscopy, shorter DAE endoscopes were developed allowing the use of conventional ERCP accessories and stents and an additional water channel allowed flushing away biliary stones and blood without the need to clear the working channel (89). Enteroscopes with a working-channel of $3.2 \mathrm{~mm}$ currently allow biliary self-expandable metal stent insertion which was impossible until recently (90). The 200-cm long DAE may be particularly helpful with Roux-en-Y bypass with a long limb. Forward viewing enteroscopes also facilitate direct cholangioscopy in patients with altered anatomy allowing introduction of the enteroscope into the biliary system after balloon dilation of the papilla followed intraductal endoscopic procedures such as biopsy sampling and stone extraction $(91,92)$. The use of a plastic cap at the tip of the enteroscope may facilitate cannulation of the papilla (93). CO2 insufflation is also recommended all cases of therapeutic endoscopy including DAE-assisted ERCP. PowerSpiral Enteroscopy-ERCP has also been described in Roux-en-Y anatomy. The speed, depth and control of insertion, short length of $168 \mathrm{~cm}$, and 3.2-mm working channel offer potential advantages compared to standard DAE (94).

\section{REFERENCES}

1. Matsumoto T, Moriyama T, Esaki M, Nakamura S, Iida M. Performance of antegrade double-balloon enteroscopy: comparison with push enteroscopy. Gastrointest Endosc. (2005) 62:392-8. doi: 10.1016/j.gie.2005.04.052

2. Bonnet S, Douard R, Malamut G, Cellier C, Wind P. Intraoperative enteroscopy in the management of obscure gastrointestinal bleeding. Dig Liver Dis. (2013) 45:277-84. doi: 10.1016/j.dld.2012.07.003

3. Appleyard M, Glukhovsky A, Swain P. Wireless-capsule diagnostic endoscopy for recurrent small-bowel bleeding. N Engl J Med. (2001) 344:232-3. doi: 10.1056/NEJM200101183440316

4. Yamamoto H, Yano $\mathrm{T}$, Kita H, Sunada K, Ido K, Sugano K. New system of double-balloon enteroscopy for diagnosis and treatment of small intestinal disorders. Gastroenterology. (2003) 125:1556; author reply 1556-7. doi: 10.1016/j.gastro.2003.03.004

5. Tsujikawa T, Saitoh Y, Andoh A, Imaeda H, Hata K, Minematsu H, et al. Novel single-balloon enteroscopy for diagnosis and treatment of

\section{FUTURE DIRECTIONS}

DAE is continuously evolving with new and improved enteroscopes allowing more complex therapeutic endoscopy procedures. PSE appears to be a promising and exciting advancement in deep enteroscopy. It may be the solution to finally assess the small bowel completely, reliably, and with relative speed all in one setting. Future randomized controlled trials will be needed to assess its ultimate benefit. PSE may be the start of an endoscopic motorized revolution that opens the world of endoscopic technology in many areas.

In the past few years, deep learning has revolutionized the field of computer vision and an increasing number of studies utilizing artificial intelligence in VCE has been published. Deep learning has achieved excellent sensitivity and specificity in detection of small bowel diseases (95). Eventually, this will translate to DAE by improving its diagnostic yield and performance. In addition, the implementation of robotics in flexible endoscopy appears to provide greater stability and controllability for complex therapeutic procedures that may eventually be applied to deep enteroscopy further expanding its therapeutic armamentarium (96).

\section{CONCLUSION}

DAE is becoming a standard tool in the evaluation and management of small bowel diseases. Particularly, DBE and SAE have proven their value and safety in large cohort studies (Table 2). The introduction of PSE may represent a major advance in small bowel endoscopy if efficacy and safety results can be replicated in larger studies. Although capsule endoscopy will remain the initial diagnostic test in most patients with suspected small bowel diseases, the future of deep enteroscopy appears promising given the efficacy, simplicity, and safety of motorized spiral enteroscopy.

\section{AUTHOR CONTRIBUTIONS}

RC, HG, and AP: conception and design. FN and HG: first draft. All authors: critical revision and editing, and final approval.

the small intestine: preliminary experiences. Endoscopy. (2008) 40:11-5. doi: 10.1055/s-2007-966976

6. Akerman PA, Agrawal D, Cantero D, Pangtay J. Spiral enteroscopy with the new DSB overtube: a novel technique for deep peroral small-bowel intubation. Endoscopy. (2008) 40:974-8. doi: 10.1055/s-0028-1103402

7. Neuhaus H, Beyna $T$, Schneider $M$, Devière J. Novel motorized spiral enteroscopy: first clinical case. VideoGIE. (2016) 1:32-3. doi: 10.1016/j.vgie.2016.08.005

8. Pérez-Cuadrado Robles E, Pinho R, González-Suárez B. Mão-de-Ferro S, Chagas C, Esteban Delgado P, et al. Small bowel enteroscopy - A joint clinical guideline by the Spanish and Portuguese small-bowel study groups. Rev Esp Enferm Dig. (2020) 112:309-18. doi: 10.17235/reed.2020.7020/2020

9. Rondonotti E, Spada C, Adler S, May A, Despott EJ, Koulaouzidis A, et al. Small-bowel capsule endoscopy and device-assisted enteroscopy for diagnosis and treatment of small-bowel disorders: European Society of Gastrointestinal Endoscopy (ESGE) Technical Review. Endoscopy. (2018) 50:423-46. doi: 10.1055/a-0576-0566 
10. Yamamoto H, Ogata H, Matsumoto T, Ohmiya N, Ohtsuka K, Watanabe $\mathrm{K}$, et al. Clinical practice guideline for enteroscopy. Dig Endosc. (2017) 29:519-46. doi: 10.1111/den.12883

11. Tanisaka Y, Ryozawa S, Mizuide M, Araki R, Fujita A, Ogawa T, et al. Status of single-balloon enteroscopy-assisted endoscopic retrograde cholangiopancreatography in patients with surgically altered anatomy: systematic review and meta-analysis on biliary interventions. Dig Endosc. (2021) 33:1034-44. doi: 10.1111/den.13878

12. Lewis BS, Waye JD. Total small bowel enteroscopy. Gastrointest Endosc. (1987) 33:435-8. doi: 10.1016/S0016-5107(87)71682-4

13. Seensalu R. The sonde exam. Gastrointest Endosc Clin N Am. (1999) 9:37-59. doi: 10.1016/S1052-5157(18)30219-8

14. Shinya H, McSherry C. Endoscopy of the small bowel. Surg Clin North Am. (1982) 62: 821-4. doi: 10.1016/S0039-6109(16)42831-8

15. Foutch PG, Sanowski RA, Kelly S. Enteroscopy: a method for detection of small bowel tumors. Am J Gastroenterol. (1985) 80:887-90.

16. May A, Nachbar L, Schneider M, Ell C. Prospective comparison of push enteroscopy and push-and-pull enteroscopy in patients with suspected small-bowel bleeding. Am J Gastroenterol. (2006) 101:2016-24. doi: 10.1111/j.1572-0241.2006.00745.x

17. Khashab MA, Okolo PI. Accessing the pancreatobiliary limb and ERCP in the bariatric patient. Gastrointest Endosc Clin N Am. (2011) 21:305-13. doi: 10.1016/j.giec.2011.02.003

18. ASGE TECHNOlOgY COMMITTEE, DiSario JA, Petersen BT, Tierney WM, Adler DG, Chand B, et al. Enteroscopes. Gastrointest Endosc. (2007) 66:872-80. doi: 10.1016/j.gie.2007.07.032

19. Gross SA. Stark ME. Initial experience with double-balloon enteroscopy at a US center. Gastrointest Endosc. (2008) 67:890-7. doi: 10.1016/j.gie.2007.07.047

20. Elena RM, Riccardo U, Rossella C, Bizzotto A, Domenico G, Guido C. Current status of device-assisted enteroscopy: technical matters, indication, limits and complications. World J Gastrointest Endosc. (2012) 4:453-61. doi: 10.4253/wjge.v4.i10.453

21. May A, Nachbar L, Ell C. Double-balloon enteroscopy (push-and-pull enteroscopy) of the small bowel: feasibility and diagnostic and therapeutic yield in patients with suspected small bowel disease. Gastrointest Endosc. (2005) 62:62-70. doi: 10.1016/S0016-5107(05)01586-5

22. Tee HP, How SH, Kaffes AJ. Learning curve for double-balloon enteroscopy: Findings from an analysis of 282 procedures. World J Gastrointest Endosc. (2012) 4:368-72. doi: 10.4253/wjge.v4.i8.368

23. Xin L, Liao Z, Jiang YP, Li ZS. Indications, detectability, positive findings, total enteroscopy, and complications of diagnostic double-balloon endoscopy: a systematic review of data over the first decade of use. Gastrointest Endosc. (2011) 74:563-70. doi: 10.1016/j.gie.2011.03.1239

24. Honda K, Mizutani T, Nakamura K, Higuchi N, Kanayama K, Sumida $\mathrm{Y}$, et al. Acute pancreatitis associated with peroral double-balloon enteroscopy: a case report. World J Gastroenterol. (2006) 12:1802-4. doi: 10.3748/wjg.v12.i11.1802

25. Honda K, Itaba S, Mizutani T, Sumida Y, Kanayama K, Higuchi N, et al. An increase in the serum amylase level in patients after peroral double-balloon enteroscopy: an association with the development of pancreatitis. Endoscopy. (2006) 38:1040-3. doi: 10.1055/s-2006-944831

26. Kopácová M, Rejchrt S, Tachecí I, Bures J. Hyperamylasemia of uncertain significance associated with oral double-balloon enteroscopy. Gastrointest Endosc. (2007) 66:1133-8. doi: 10.1016/j.gie.2007.03.1085

27. Aktas H, Mensink PBF, Haringsma J, Kuipers EJ. Low incidence of hyperamylasemia after proximal double-balloon enteroscopy: has the insertion technique improved? Endoscopy. (2009) 41:670-3. doi: 10.1055/s-0029-1214976

28. Möschler O, May A, Müller MK, Ell C, German DBE. Study Group. Complications in and performance of double-balloon enteroscopy (DBE): results from a large prospective DBE database in Germany. Endoscopy. (2011) 43:484-9. doi: 10.1055/s-0030-1256249

29. Gerson LB, Tokar J, Chiorean M, Lo S, Decker GA, Cave D, et al. Complications associated with double balloon enteroscopy at nine US centers. Clin Gastroenterol Hepatol. (2009) 7:1177-82, 1182.e1-3. doi: 10.1016/j.cgh.2009.07.005
30. Mensink PBF, Haringsma J, Kucharzik T, Cellier C, Pérez-Cuadrado E, Mönkemüller $\mathrm{K}$, et al. Complications of double balloon enteroscopy: a multicenter survey. Endoscopy. (2007) 39:613-5. doi: 10.1055/s-2007-966444

31. Byeon JS, Mann NK, Jamil LH, Lo SK. Double balloon enteroscopy can be safely done in elderly patients with significant co-morbidities. J Gastroenterol Hepatol. (2012) 27:1831-6. doi: 10.1111/j.1440-1746.2012.07284.x

32. Sidhu R, Sanders DS. Double-balloon enteroscopy in the elderly with obscure gastrointestinal bleeding: safety and feasibility. Eur J Gastroenterol Hepatol. (2013) 25:1230-4. doi: 10.1097/MEG.0b013e3283630f1b

33. Upchurch BR, Vargo JJ. Single-balloon enteroscopy. Gastrointest Endosc Clin N Am. (2009) 19:335-47. doi: 10.1016/j.giec.2009.04.010

34. Kawamura T, Yasuda K, Tanaka K, Uno K, Ueda M, Sanada K, et al. Clinical evaluation of a newly developed single-balloon enteroscope. Gastrointest Endosc. (2008) 68:1112-6. doi: 10.1016/j.gie.2008.03.1063

35. Lenz P, Domagk D. Double- vs. single-balloon vs. spiral enteroscopy. Best Pract Res Clin Gastroenterol. (2012) 26:303-13. doi: 10.1016/j.bpg.2012.01.021

36. Takano N, Yamada A, Watabe H, Togo G, Yamaji Y, Yoshida H, et al. Singleballoon versus double-balloon endoscopy for achieving total enteroscopy: a randomized, controlled trial. Gastrointest Endosc. (2011) 73:734-9. doi: 10.1016/j.gie.2010.10.047

37. Khashab MA, Lennon AM, Dunbar KB, Singh VK, Chandrasekhara V, Giday $\mathrm{S}$, et al. A comparative evaluation of single-balloon enteroscopy and spiral enteroscopy for patients with mid-gut disorders. Gastrointest Endosc. (2010) 72:766-72. doi: 10.1016/j.gie.2010.04.043

38. Upchurch BR, Sanaka MR, Lopez AR, Vargo JJ. The clinical utility of single-balloon enteroscopy: a single-center experience of 172 procedures. Gastrointest Endosc. (2010) 71:1218-23. doi: 10.1016/j.gie.2010.01.012

39. Tominaga K, Iida T, Nakamura Y, Nagao J, Yokouchi Y, Maetani I. Small intestinal perforation of endoscopically unrecognized lesions during peroral single-balloon enteroscopy. Endoscopy. (2008) 40 Suppl 2:E213-214. doi: 10.1055/s-2008-1077405

40. Kav T, Balaban Y, Bayraktar Y. The power suction maneuver in singleballoon enteroscopy. Endoscopy. (2008) 40:961-2; author reply 962. doi: 10.1055/s-2008-1077631

41. Akerman PA, Agrawal D, Chen W, Cantero D, Avila J, Pangtay J. Spiral enteroscopy: a novel method of enteroscopy by using the Endo-Ease Discovery SB overtube and a pediatric colonoscope. Gastrointest Endosc. (2009) 69:327-32. doi: 10.1016/j.gie.2008.07.042

42. Baniya R, Upadhaya S, Subedi SC, Khan J, Sharma P, Mohammed TS, et al. Balloon enteroscopy versus spiral enteroscopy for small-bowel disorders: a systematic review and meta-analysis. Gastrointest Endosc. (2017) 86:9971005. doi: 10.1016/j.gie.2017.06.015

43. Messer I, May A, Manner H, Ell C. Prospective, randomized, single-center trial comparing double-balloon enteroscopy and spiral enteroscopy in patients with suspected small-bowel disorders. Gastrointest Endosc. (2013) 77:241-9. doi: 10.1016/j.gie.2012.08.020

44. Schneider M, Höllerich J, Beyna T. Device-assisted enteroscopy: a review of available techniques and upcoming new technologies. World J Gastroenterol. (2019) 25:3538-45. doi: 10.3748/wjg.v25.i27.3538

45. Buscaglia JM, Dunbar KB, Okolo PI, Judah J, Akerman PA, Cantero D, et al. The spiral enteroscopy training initiative: results of a prospective study evaluating the discovery SB overtube device during small bowel enteroscopy (with video). Endoscopy. (2009) 41:194-9. doi: 10.1055/s-0028-1119602

46. Kumbhari V, Storm AC, Khashab MA, Canto MI, Saxena P, Akshintala VS, et al. Deep enteroscopy with standard endoscopes using a novel through-thescope balloon. Endoscopy. (2014) 46:685-9. doi: 10.1055/s-0034-1365464

47. Kumbhari V, Saxena P, Khashab MA. A new through-the-scope balloonassisted deep enteroscopy platform. Gastrointest Endosc. (2014) 79:694. doi: 10.1016/j.gie.2013.10.034

48. Beyna T, Schneider M, Pullmann D, Gerges C, Kandler J, Neuhaus H. Motorized spiral colonoscopy: a first single-center feasibility trial. Endoscopy. (2018) 50:518-23. doi: 10.1055/s-0043-123577

49. Beyna T, Arvanitakis M, Schneider M, Gerges C, Böing D, Devière J, et al. Motorised spiral enteroscopy: first prospective clinical feasibility study. Gut. (2021) 70:261-7. doi: 10.1136/gutjnl-2019-319908

50. Prasad M, Prasad VGM, Sangameswaran A, Verghese SC, Murthy V, Prasad M. Set al. A spiraling journey into the small bowel: a case series 
of novel motorized power spiral enteroscopies. VideoGIE. (2020) 5:591-6. doi: 10.1016/j.vgie.2020.08.001

51. Beyna T, Arvanitakis M, Schneider M, Gerges C, Hoellerich J, Devière J, et al. Total motorized spiral enteroscopy: first prospective clinical feasibility trial. Gastrointest Endosc. (2021) 93:1362-70. doi: 10.1016/j.gie.2020.10.028

52. Ramchandani M, Rughwani H, Inavolu P, Singh AP, Tevethia HV, Jagtap $\mathrm{N}$, et al. Diagnostic yield and therapeutic impact of novel motorized spiral enteroscopy in small-bowel disorders: a single-center, real-world experience from a tertiary care hospital (with video). Gastrointest Endosc. (2021) 93:61626. doi: 10.1016/j.gie.2020.07.001

53. ASGE Standards of Practice Committee, Gurudu SR, Bruining DH, Acosta RD, Eloubeidi MA, Faulx AL, et al. The role of endoscopy in the management of suspected small-bowel bleeding. Gastrointest Endosc. (2017) 85:22-31. doi: $10.1016 /$ j.gie.2016.06.013

54. Gralnek IM. Obscure-overt gastrointestinal bleeding. Gastroenterology. (2005) 128:1424-30. doi: 10.1053/j.gastro.2005.03.067

55. Ramchandani M, Reddy DN, Gupta R, Lakhtakia S, Tandan M, Rao GV, et al. Diagnostic yield and therapeutic impact of single-balloon enteroscopy: series of 106 cases. J Gastroenterol Hepatol. (2009) 24:1631-8. doi: 10.1111/j.1440-1746.2009.05936.x

56. Mönkemüller K, Weigt J, Treiber G, Kolfenbach S, Kahl S. Röcken C, et al. Diagnostic and therapeutic impact of double-balloon enteroscopy. Endoscopy. (2006) 38:67-72. doi: 10.1055/s-2005-921190

57. Somsouk M, Gralnek IM, Inadomi JM. Management of obscure occult gastrointestinal bleeding: a cost-minimization analysis. Clin Gastroenterol Hepatol. (2008) 6:661-70. doi: 10.1016/j.cgh.2008.02.033

58. Gerson L, Kamal A. Cost-effectiveness analysis of management strategies for obscure GI bleeding. Gastrointest Endosc. (2008) 68:920-36. doi: 10.1016/j.gie.2008.01.035

59. Samaha E, Rahmi G, Landi B, Lorenceau-Savale C, Malamut G, Canard JM, et al. Long-term outcome of patients treated with double balloon enteroscopy for small bowel vascular lesions. Am J Gastroenterol. (2012) 107:240-6. doi: 10.1038/ajg.2011.325

60. May A, Friesing-Sosnik T, Manner H, Pohl J, Ell C. Long-term outcome after argon plasma coagulation of small-bowel lesions using double-balloon enteroscopy in patients with mid-gastrointestinal bleeding. Endoscopy. (2011) 43:759-65. doi: 10.1055/s-0030-1256388

61. Madisch A, Schmolders J, Brückner S, Aust D, Miehlke S. Less favorable clinical outcome after diagnostic and interventional double balloon enteroscopy in patients with suspected small-bowel bleeding? Endoscopy. (2008) 40:731-4. doi: 10.1055/s-2008-1077521

62. Schottenfeld D, Beebe-Dimmer JL, Vigneau FD. The epidemiology and pathogenesis of neoplasia in the small intestine. Ann Epidemiol. (2009) 19:5869. doi: 10.1016/j.annepidem.2008.10.004

63. Imaoka H, Higaki N, Kumagi T, Miyaike J, Ohmoto M, Yamauchi K, et al. Characteristics of small bowel tumors detected by double balloon endoscopy. Dig Dis Sci. (2011) 56:2366-71. doi: 10.1007/s10620-011-1741-8

64. Mitsui K, Tanaka S, Yamamoto H, Kobayashi T, Ehara A, Yano T, et al. Role of double-balloon endoscopy in the diagnosis of small-bowel tumors: the first Japanese multicenter study. Gastrointest Endosc. (2009) 70:498-504. doi: 10.1016/j.gie.2008.12.242

65. Islam RS, Leighton JA, Pasha SF. Evaluation and management of small-bowel tumors in the era of deep enteroscopy. Gastrointest Endosc. (2014) 79:732-40. doi: 10.1016/j.gie.2013.11.003

66. Pasha SF, Leighton JA, Das A, Harrison ME, Decker GA, Fleischer DE, et al. Double-balloon enteroscopy and capsule endoscopy have comparable diagnostic yield in small-bowel disease: a meta-analysis. Clin Gastroenterol Hepatol. (2008) 6:671-6. doi: 10.1016/j.cgh.2008.01.005

67. Lewis BS, Eisen GM, Friedman SA. pooled analysis to evaluate results of capsule endoscopy trials. Endoscopy. (2005) 37:960-5. doi: $10.1055 / \mathrm{s}-2005-870353$

68. Kopácová M, Bures J, Ferko A, Tachecí I, Rejchrt S. Comparison of intraoperative enteroscopy and double-balloon enteroscopy for the diagnosis and treatment of Peutz-Jeghers syndrome. Surg Endosc. (2010) 24:1904-10. doi: 10.1007/s00464-009-0868-6

69. Sakamoto H, Yamamoto H, Hayashi Y, Yano T, Miyata T, Nishimura N, et al. Nonsurgical management of small-bowel polyps in Peutz-Jeghers syndrome with extensive polypectomy by using double-balloon endoscopy. Gastrointest Endosc. (2011) 74:328-33. doi: 10.1016/j.gie.2011.04.001

70. Heine GD, Hadithi M, Groenen MJ, Kuipers EJ, Jacobs MA, Mulder CJ. Double-balloon enteroscopy: indications, diagnostic yield, and complications in a series of 275 patients with suspected small-bowel disease. Endoscopy. (2006) 38:42-8. doi: 10.1055/s-2005-921188

71. Mensink PBF, Aktas H, Zelinkova Z, West RL, Kuipers EJ, van der Woude CJ. Impact of double-balloon enteroscopy findings on the management of Crohn's disease. Scand J Gastroenterol. (2010) 45:483-9. doi: $10.3109 / 00365520903563774$

72. Skamnelos A, Lazaridis N, Vlachou E, Koukias N, Apostolopoulos P, Murino $A$, et al. The role of small-bowel endoscopy in inflammatory bowel disease: an updated review on the state-of-the-art in 2021. Ann Gastroenterol. (2021) 34:599-611. doi: 10.20524/aog.2021.0652

73. Mensink PBF, Groenen MJ, van Buuren HR, Kuipers EJ, van der Woude CJ. Double-balloon enteroscopy in Crohn's disease patients suspected of small bowel activity: findings and clinical impact. J Gastroenterol. (2009) 44:271-6. doi: 10.1007/s00535-009-0011-4

74. Despott EJ, Gupta A, Burling D, Tripoli E, Konieczko K, Hart A, et al. Effective dilation of small-bowel strictures by double-balloon enteroscopy in patients with symptomatic Crohn's disease (with video). Gastrointest Endosc. (2009) 70:1030-6. doi: 10.1016/j.gie.2009.05.005

75. Moreels TG, Macken EJ, Pelckmans PA. Renewed attention for overtube-assisted colonoscopy to prevent incomplete endoscopic examination of the colon. Dis Colon Rectum. (2013) 56:1013-8. doi: 10.1097/DCR.0b013e3182962636

76. Tan M, Lahiff C, Bassett P, Bailey AA, East JE. Efficacy of Balloon overtubeassisted colonoscopy in patients with incomplete or previous difficult colonoscopies: a meta-analysis. Clin Gastroenterol Hepatol. (2017) 15:162830. doi: $10.1016 /$ j.cgh. 2017.04 .023

77. Yamada A, Watabe H, Takano N, Togo G, Yamaji Y, Yoshida H, et al. Utility of single and double balloon endoscopy in patients with difficult colonoscopy: a randomized controlled trial. World J Gastroenterol. (2013) 19:4732-6. doi: 10.3748/wjg.v19.i29.4732

78. Schembre DB, Ross AS, Gluck MN, Brandabur JJ, McCormick SE, Lin OS. Spiral overtube-assisted colonoscopy after incomplete colonoscopy in the redundant colon. Gastrointest Endosc. (2011) 73:515-9. doi: 10.1016/j.gie.2010.11.047

79. Ohya T, Ohata K, Sumiyama K, Tsuji Y, Koba I, Matsuhashi N, et al. Balloon overtube-guided colorectal endoscopic submucosal dissection. World J Gastroenterol. (2009) 15:6086-90. doi: 10.3748/wjg.15.6086

80. Kawamura T, Uno K, Tanaka K, Yasuda K. Current status of single-balloon enteroscopy: insertability and clinical applications. World $J$ Gastrointest Endosc. (2015) 7:59-65. doi: 10.4253/wjge.v7.i1.59

81. Kuga R, Safatle-Ribeiro AV, Faintuch J, Ishida RK, Furuya CK, Garrido AB, et al. Endoscopic findings in the excluded stomach after Roux-en-Y gastric bypass surgery. Arch Surg. (2007) 142:942-6. doi: 10.1001/archsurg.142.10.942

82. Law R, Wong Kee Song LM, Petersen BT, Baron TH. Single-session ERCP in patients with previous Roux-en-Y gastric bypass using percutaneous-assisted transprosthetic endoscopic therapy: a case series. Endoscopy. (2013) 45:671-5. doi: $10.1055 / \mathrm{s}-0033-1344029$

83. Cai JX, Diehl DL, Kiesslich R, Storm AC, El Zein MH, Tieu AH, et al. A multicenter experience of through-the-scope balloon-assisted enteroscopy in surgically altered gastrointestinal anatomy. Surg Endosc. (2017) 31:2753-62. doi: $10.1007 / \mathrm{s} 00464-016-5282-2$

84. Skinner M, Peter S, Wilcox CM, Mönkemüller K. Diagnostic and therapeutic utility of double-balloon enteroscopy for obscure GI bleeding in patients with surgically altered upper GI anatomy. Gastrointest Endosc. (2014) 80:181-6. doi: 10.1016/j.gie.2014.02.1034

85. Popa D, Ramesh J, Peter S, Wilcox CM, Mönkemüller K. Small bowel stent-in-stent placement for malignant small bowel obstruction using a balloon-assisted overtube technique. Clin Endosc. (2014) 47:108-11. doi: $10.5946 /$ ce.2014.47.1.108

86. Onyimba F, Kumbhari V, Tieu A, Cai J, Abdegelil A, Reddy P. Benign distal jejunal stricture treated by a partially covered esophageal stent with the use of spiral enteroscopy. Endoscopy. (2015) 47 (Suppl 1 UCTN):E172. doi: $10.1055 / \mathrm{s}-0035-1547070$ 
87. Moreels TG. Altered anatomy: enteroscopy and ERCP procedure. Best Pract Res Clin Gastroenterol. (2012) 26:347-57. doi: 10.1016/j.bpg.2012.03.003

88. Skinner M, Popa D, Neumann H, Wilcox CM, Mönkemüller K. ERCP with the overtube-assisted enteroscopy technique: a systematic review. Endoscopy. (2014) 46:560-72. doi: 10.1055/s-0034-1365698

89. Moreels TG, Kouinche Madenko N, Taha A, Piessevaux H, Deprez PH. Therapeutic enteroscopy using a new single-balloon enteroscope: a case series. Endosc Int Open. (2016) 4:E918-921. doi: 10.1055/s-0042-111205

90. Yamauchi H, Kida M, Okuwaki K, Miyazawa S, Iwai T, Imaizumi H, et al. A Case Series: Outcomes of Endoscopic Biliary Self-Expandable Metal Stent for Malignant Biliary Obstruction with Surgically Altered Anatomy. Dig Dis Sci. (2016) 61:2436-41. doi: 10.1007/s10620-016-4148-8

91. Andrade de. Paulo G, Bastos VR, da Costa Martins B, Safatle-Ribeiro AV, Gusmon CC, Simas de Lima M, et al. Balloon enteroscopyassisted ERCP and cholangioscopy. Gastrointest Endosc. (2016) 84:856-7. doi: 10.1016/j.gie.2016.05.029

92. Tsujino T, Lee JG. Electrohydraulic lithotripsy for large bile duct stones under direct cholangioscopy using double-balloon enteroscopy. Dig Endosc. (2016) 28:104. doi: 10.1111/den.12558

93. Trindade AJ, Mella JM, Slattery E, Cohen J, Dickstein J, Garud SS, et al. Use of a cap in single-balloon enteroscopy-assisted endoscopic retrograde cholangiography. Endoscopy. (2015) 47:453-6. doi: 10.1055/s-0034-1391077

94. Beyna T, Schneider M, Höllerich J, Neuhaus H. Motorized spiral enteroscopy-assisted ERCP after Roux-en-Y reconstructive surgery and bilioenteric anastomosis: first clinical case. VideoGIE. (2020) 5:311-3. doi: 10.1016/j.vgie.2020.03.016
95. Soffer S, Klang E, Shimon O, Nachmias N, Eliakim R, Ben-Horin S, et al. Deep learning for wireless capsule endoscopy: a systematic review and meta-analysis. Gastrointest Endoscopy. (2020) 92:831-839.e8. doi: 10.1016/j.gie.2020. 04.039

96. Kaan HL, Ho KY. Clinical adoption of robotics in endoscopy: challenges and solutions. JGH Open. (2020) 4:790-4. doi: 10.1002/jgh3.12412

Conflict of Interest: The authors declare that the research was conducted in the absence of any commercial or financial relationships that could be construed as a potential conflict of interest.

Publisher's Note: All claims expressed in this article are solely those of the authors and do not necessarily represent those of their affiliated organizations, or those of the publisher, the editors and the reviewers. Any product that may be evaluated in this article, or claim that may be made by its manufacturer, is not guaranteed or endorsed by the publisher.

Copyright $\odot 2021$ Nehme, Goyal, Perisetti, Tharian, Sharma, Tham and Chhabra. This is an open-access article distributed under the terms of the Creative Commons Attribution License (CC BY). The use, distribution or reproduction in other forums is permitted, provided the original author(s) and the copyright owner(s) are credited and that the original publication in this journal is cited, in accordance with accepted academic practice. No use, distribution or reproduction is permitted which does not comply with these terms. 